\title{
Using science, making policy: what should we worry about?
}

\author{
Eleonora Montuschi ${ }^{1,2}$
}

Received: 27 August 2015 / Accepted: 7 March 2016 / Published online: 8 April 2016

C) The Author(s) 2016. This article is published with open access at Springerlink.com

\begin{abstract}
How does science enter policy making, and for what purpose? Surely consulting scientific facts in making policy is done with a view to making policy decisions more reliable, and ultimately more objective. In this paper I address the way/s by which science contributes to achieving objectivity in policy making and social debate, and argue that objectivity is not exhausted by what scientific evidence contributes to either. In policy making and social debates, scientific evidence is taken into account alongside other relevant factors (political, social, economic, ethical, etc.). Such complex contexts of practical interaction constitute a challenge both for the objectivity of scientific evidence (how far should science let extra-scientific factors interfere with scientific facts, without endangering the objectivity of evidence?), and for the objectivity of the role of the scientist in the policy-making process (is he/she only to inform policy, and only on matters of scientific evidence? Or should they also ultimately advise on what to do, running the risk of becoming partial on matters of evidence?) I analyse a case study - the ongoing debate over the spread of bovine TB in the UK - that displays some of the worries and several of the aspects we ought to keep in mind when we bring scientific objectivity to bear on social debate and policy making. I argue in favour of a picture where scientific objectivity enters a productive and effective dialogue with practical objectivity.
\end{abstract}

Keywords Objectivity (scientific, practical) $\cdot$ Policy-making $\cdot$ Evidence $\cdot$ Scientific advice $\cdot$ Disagreement $\cdot$ Balance of judgement

Eleonora Montuschi

e.montuschi@1se.ac.uk

1 Department of Philosophy and Cultural Heritage, Ca' Foscari University of Venice,

Dorsoduro 3484/D, 30123 Venice, Italy

2 Centre for Philosophy of Natural and Social Science, London School of Economics and Political Science, Houghton St., London WC2 2AE, UK 


\section{Introduction}

In this paper I look at how science enters policy decision-making. The increasingly influential evidence-based policy and practice (EBPP) movement teaches, for example, that basing policy on scientific knowledge is the key to making policy decisions more objective. Who could be opposed to this? Consulting scientific facts when we make policy surely makes policy decisions more reliable, ultimately more objective. In what follows I analyse a case study - the ongoing debate over the spread of bovine TB in the UK - where science plays a central role: it helps formulate a policy package intended to reduce effectively, and eventually eradicate, the insurgence and dissemination of the disease. Science is asked to contribute well-grounded answers to causal questions (eg. are badgers responsible, and in what percentage, for the spreading of the disease in cattle) and predictions (eg, is culling badgers, in forms and degrees to be qualified, an effective way to contain and/or eradicate the disease). These are the areas where science is expected to provide 'objective' results.

The role of science in this debate appears nonetheless controversial for at least two reasons. First, scientists disagree on a series of matters of fact, in particular on some fact-informed predictions. So at least at first sight, it might look as if resorting to science adds problems to policy making rather than providing a solid, robust basis of uncontroversial evidence policymakers can operate from. Objectivity, prima facie, entails agreement on facts! Second, in composing a policy package regarding bovine TB scientific facts are not the only ones to be consulted. There is inevitably a host of other, equally relevant factual considerations: stakeholders' interests such as farmers' and animal right activists'; public values such as the preservation of wildlife, or the humaneness of culling; economic factors such as the costs of culling, or of changing existing farming practices; subject-specific expertise such as veterinary knowledge; the practical implementation of techniques and technologies of culling; etc. All these are impending factors that can hardly be ignored when it comes deciding what to do regarding bovine TB. Separating out 'scientific facts' from the context where they are asked to act as evidence would appear a difficult and contentious strategy to pursue in practice: the objectivity of decisions would appear to suffer. And yet, were this context to be taken into account, scientific judgement would be feared to be at a loss in terms of its own objectivity.

These two aspects of controversy - that emerge clearly from the case study analysed in this paper - highlight two relevant questions. The first regards how science takes part in policy decision making: should science be asked only to inform policy, and only on matters of scientific evidence? Or should it also ultimately advise on what to do, knowing that this what to do depends on creating a balance between scientific evidence and a complex of factors (values, interests, judgement, practicalities) within, and far beyond without, the range of science? This query is itself indicative of a difficult question concerning the contribution of science to policy making: if science is brought in to make policy decisions more objective, but the objectivity of these decisions depends on a balance of factors that goes beyond the immediately 'scientific', does objectivity perhaps go astray? 
The second question regards how policy sees the process of decision-making on matters of interest. In a policy context we want to make the following claims (possibly at the same time):

a. that a policy decision is objective because of the support given by scientific facts (and it chooses to be supported by those facts)

b. that a policy decision is objective because it fairly takes into account different facts and realities of practice

c. that a policy decision is objective when it also makes a decision about scientific evidence (about how to use it).

Does objectivity go astray along this sequence of practical decisions over scientific evidence - its definition, its use, its role? Is even the best scientific evidence able to reassure us that objectivity is still in the picture? And most of all, are we dealing with the same concept of objectivity when we shift from science to policy?

The sense of alarm, of uneasiness, conveyed by these two queries will be used in this paper as a guide to find out what is at stake when we show concern about loosing objectivity in policy deliberation. What are we afraid of when we worry that objectivity may be out the window if we let values, interests, judgement and practicalities interfere with scientific outcomes, and play a role in policy making? Are these fears real? How can they be warded off?

There are two reasons for this way of proceeding in my argument. First, I believe it is impossible, as well as unwise, to formulate a definition of objectivity in policy making that can be extracted from a general theory of objectivity - as if objectivity were an overarching, timeless standard against which to articulate and measure domaindependent varieties of it. Work in history of science in the last couple of decades has shown how the concept of objectivity has changed dramatically across time and place as different threats have been felt to loom (Daston and Galison 2007).

Second, science provides $a$ model of objectivity, and it staves off only some of the dangers that 'objectivity' is supposed to protect us from. The various debates in philosophy of science (and philosophy of social science), from the XX century onwards, that were aimed at identifying and articulating a viable notion of objectivity for the sciences, were framed within a particular image of knowledge wherein that notion made sense for science. ${ }^{1}$ According to traditional views, to be objective is to represent the world 'as it really is' (ontological assumption), to avoid values, ideologies and subjective interests in the formulation of theories (epistemological assumption), and to favour procedures of inquiry that, on the basis of the previous two assumptions, guarantee an accurate pursuit of knowledge (methodological assumption). Science seems perfectly to instantiate this scenario. There are facts in nature (and arguably in society) that science can have access to by means of methodological tools (experiment; measurement) that accurately and rigorously describe those facts, as well as independently of who uses them. 'Mechanical objectivity' established itself as the ideal image of how science operates, and by default of all those disciplines that were to be taken as objective. However, the various XX-century philosophical debates on objectivity challenged this very ideal and, by looking at both the history and practice of science,

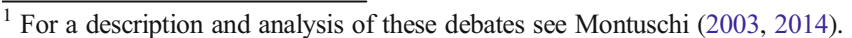


the assumptions on which that ideal rests were variously rethought, and sometimes seriously criticised.

There are two aspects, out of the range of issues highlighted by these debates, that are important here to bring forward, in view of what will be discussed and argued for in this paper.

First, the criticism to scientific objectivity provided by the history and practice of science concerns mainly the context of knowledge production. What is at stake is, for example, whether the facts that science deals with are real or constructed (discovered or invented); what it means for scientific inquiry or scientific theories to be value-laden; or whether methods that are deemed best in principle are equally so in scientific practice, and across different practices. The traditional debates on objectivity did not question how science, with whatever baggage it carries with it, comes to be used outside its own fields of inquiry and discovery, and confronts the challenges that extra-scientific practices (eg., policy making, or social debates, or legal verdicts) put its way when it is called upon to offer its contribution to social understanding and decision-making. Emphasising the distinction between production and use is important, as this paper will concentrate on the latter: it will focus on what happens to objectivity (and scientific objectivity) when science is used outside its realm of production. It is important particularly because, as we will see, using science outside the contexts where science is produced creates additional problems for science and for how it works in those contexts. Asking the right questions, collecting the appropriate evidence, predicting what the most effective thing to do is: all this goes well beyond producing true facts and assembling empirically confirmed evidence.

Second, and as already mentioned, scientific objectivity is not the model of objectivity. Focused mainly on the use of experiment and measurement, scientific objectivity is devised to fence us off imprecision, unfalsifiability and speculation about facts. It is not however, and therefore it cannot defend us, on all the fronts where 'objectivity' is asked to serve as a protection from arbitrary behaviour. When scientific knowledge enters the public domain there is however a danger that this special conception of objectivity that guides the sciences takes over, ignoring the practices and conceptions of objectivity that protect us from other threats we feel in other domains, from the political arena to local knowledge to common sense to subject-specific expertise. The list of worries as regards losing objectivity widens inevitably as a consequence: partiality first of all (as mentioned above, if science enters the political arena can it still be objective, i.e. in this sense 'impartial'?), closely followed by self-interest (corporate interest), prejudice, unfair judgement, unaccountability. This of course does not mean that science is of no use in policy making, or that science itself is free from those further worries. It means though, as will be argued in the paper, that some interesting lessons from its limited use can be learnt in view of making policy decisions that use science a reliable, safer process.

So, in the light of the scenario just sketched out, here in outline is the argument I will pursue in this paper:

1. Science enters policy making with the expectation that it makes policy decisions more objective (it answers causal questions and makes fact-informed predictions, and by so doing it provides policy decisions with a robust basis of evidence); 
2. This expectation is immediately confronted by two related problems: disagreement on matters of scientific fact (or on matters informed by those facts) and disagreement on how engaged science should be in the policy deliberation process where other matters (other than those brought in by science) are to be considered;

3. These two problems become a source of worry: science might not deliver robust facts, and it might not be impartial in delivering them. We worry that the objectivity science promises to policy goes out of the window.

4. Addressing this worry, and analysing how it enters both scientific predictions and the making of policy decisions on the basis of those predictions, will bring us to realise that such a worry does not necessarily justify our concern about the objectivity of the process in question.

My conclusion is a plea for a theory of 'practical objectivity', built on a balance of intervening factors and on an open dialogue among the parties. This I envisage as a response to those that doubt objectivity is a constraining feature in policy making. On its own part, scientific objectivity does not set itself in opposition with practical objectivity; it is rather to be used in the context of it. Science must respond to the requests put on it by the practices that invoke its use, while its role and limits must be placed within the wider framework of those practices. As I will hint at in the conclusions, using the objectivity of science in matters of social concern must be part of a public conception of what is correct and reasonable to use in the resolutions of those very matters and the decisions they call for.

To articulate my argument I will use, as mentioned above, a case study that displays some of the worries and several of the aspects we ought to keep in mind when we bring scientific objectivity to bear on social debate and policy making.

\section{A Case Study: The spread of bovine tuberculosis in the UK}

By the 1930s bovine TB already was already identified as a major public health risk: Mycobacterium bovis spread in milk, which was drunk unpasteurized. The infection would thus pass easily into the human population. Over 50,000 new cases of human TB were recorded each year in Great Britain in those days, and it was estimated that 2500 people were dying annually from TB caused by $M$. bovis. ${ }^{2}$

An early form of control consisted in programmes of slaughtering infected cattle (made compulsory between 1950s and 1980s) and routine pasteurization. However, despite all this, the incidence of bovine TB has steadily increased over the last 30 years, becoming endemic in the southwest of the UK, in southwest Wales and in parts of central England.

\subsection{Causes}

Science was put to study the causes of the spread of the disease. A major cause suggested by scientific studies is cattle to cattle transmission (Gilbert et al. 2005; Gopal et al. 2006).

\footnotetext{
${ }^{2}$ The disease spreads primarily through the exchange of respiratory secretions between infected and uninfected animals. Bacteria released into the air through coughing and sneezing can spread the disease to uninfected animals.
} 
Work in this area has been focusing on monitoring migrations and movements of cattle, recording them since 1998 in a 'Cattle Tracing System' (CTS) data archive, and simulation models have been used to predict possible future distribution of the disease.

However, there is also a competing view that has been gaining credit since 1971, when a dead badger infected with bovine TB was discovered on a farm where an outbreak of the disease had occurred in the cattle herd. It was then suggested that badgers might be a significant cause of the spread of the disease.

The UK government commissioned two major official reports, the 1998 Krebs Report and the 2007 Bourne Report. They became instrumental in turning the badger hypothesis into a fierce political and social controversy. The 1998 Report, composed by the 'Independent Scientific Review Group' (ISG), led at the time by Professor John Krebs (from now on Krebs et al. 1998), reviewed the evidence, available at the time, of a link between TB in badgers and in cattle and the conclusion reached was that "the sum of evidence strongly supports the view that, in Britain, badgers are a significant source of infection in cattle..." Although it was accepted that some evidence was only 'indirect' (it pointed at correlations rather than direct 'demonstrations of cause and effect') 'in total the available evidence, including the effects of completely removing badgers from certain areas, is compelling" (Krebs et al.1998, p.6).

If badgers are a significant source of disease, then culling badgers could be the best course of action in view of reducing the spread of the disease. The Ministry of Agriculture Fisheries and Food then implemented, in succession, a variety of policies for killing badgers in order to control the disease in cattle.

It was, however, impossible at the time to assess the effectiveness of these policies, since no experiments had been set out to check how much of a difference killing or not killing badgers actually made on the spread of the disease. As remarked in the 1997 report, "It is not (...) possible to state quantitatively what contribution badgers make to cattle infection" (Krebs et al. 1998, p.6). More empirical data were necessary.

\subsection{The evidence}

A Randomised Badger Culling Trial (RBCT) was recommended in order to explore further whether culling badgers would have a significant effect on TB in cattle. The trial took place between 1998 and 2007 and was overseen and then analysed again by the ISG now chaired by Prof John Bourne, a member of the Royal College of Veterinary Surgeons, also made responsible for choosing the 'hot spots' (areas of highest risk of repeated infection) where the trial cull could be carried out.

The trial took place in thirty $100-\mathrm{km}^{2}$, areas of England, which were grouped into ten sets of three areas ('triplets') and involved three treatments: proactive culling of badgers, reactive culling following the identification of TB, and no culling. The results of the trial were published in a Report (from now on, Bourne et al. 2007b), where the main conclusion was that

"badger culling cannot meaningfully contribute to the future control of the disease. Although badgers do contribute to the disease in cattle, culling badgers is not the solution - and indeed it might even make things worse" (Bourne et al. 2007b, p.15) 
The reason given for 'making things worse' is a phenomenon called 'perturbation'. Although it was observed that TB outbreaks in cattle declined inside the proactive badger cull areas (by $25 \%$ at the core of the area, decreasing up to $16 \%$ towards the edges of the area), ${ }^{3}$ an increase occurred in the surrounding $2 \mathrm{~km}$ area. Badgers live in socially tight networks. Once the stability of these networks is 'perturbed' by a cull, movements of badgers increase and behavioural changes in badgers occur, making the situation volatile and unpredictable. Badgers, including infected ones, would flee from the cull areas and bring the disease to farms with no incidences of infected cattle.

Measures of control on cattle are also analysed in the report, and it is argued that their monitoring and improvement are more likely to bring better disease management and ultimately more successful policies. We read in the report:

"It is unfortunate that agricultural and veterinary leaders continue to believe, in spite of overwhelming scientific evidence to the contrary, that the main approach to cattle TB control must involve some form of budger population control. (...) Ministers clearly have demanding policy questions to address, but we believe that they now have sufficiently robust and extensive evidence to enable informed decisions to be made" (Bourne et al. 2007b, p.15).

The evidence presented in the report is defined as 'robust' and 'extensive' not just because it relies on the outcomes of a 10-year experimental trial. In the report we are also reassured that first, the evidence was assembled "in accordance with good scientific practice", i.e. by working to clear methodological protocols, publishing findings in leading peer reviewed journals, releasing all relevant data to any interested members of the scientific community, allowing all aspects of the RBCT being audited independently of ISG and Defra and the results being made public. (Bourne et al. 2007b, p.13). Second, it is emphasised that the evidence was acquired from different sources: because of the complex nature of the problem addressed it appeared mandatory to ISG scientists to dig more widely than "simply the delivery of ultimate findings from a scientifically designed RBCT." (Bourne et al. 2007b, p.32). The 'evidence base' includes, besides a wide natural science grounding in genetic, epidemiological, ecological and environmental studies of the problem, also input from economic, social, practical (such as the technologies of disease management) and animal welfare issues that are deemed critical in assessing the effectiveness of culling as a measure of TB control. Such a wider basis is what is needed, we read in the report, if policy is to address competently the question of whether badger culling is likely to reduce the number of herd breakdowns. In other words, what is needed is a wide ranging, integrated "clear evidence of what is feasible in practice and predictable in outcome" (Bourne et al. 2007b, p.32).

Detailed attention is given for example to the economic aspects of TB control, as it is recognised that the 'efficiency' of the measures to adopt also include a relevant economic dimension (do the costs of a cull outweight the benefits). The cost and the benefits are not only of a monetary or financial type: what about the preservation of diversity in wildlife as valued by society; or the ecological changes due to badger removal from the countryside; or police involvement to address the need for security and protection from

\footnotetext{
${ }_{3}^{3}$ The RBCT shows that reactive culling produced a $20 \%$ increase of incidence of bovine TB, largely due to the same reason.
} 
protestors? Benefits are also not equally distributed among the stakeholders: a cull programme might well appear worthwhile for livestock farmers or for the suppliers of disease control services but not so for, say, arable farmers, or wildlife interest groups, or the taxpayers. For these reasons the framework of analysis must be "wide ranging and detailed" in order to secure "a balanced overall evaluation" (Bourne et al. 2007b, p.153). This goes not only for economic frameworks that aim to be informative and useful, but also - as specified above - for scientific advice to policymakers in general.

\subsection{Policy action}

The political response to the Bourne et al. report was to authorise badger culling (Defra 2011). On 14 December 2011 it was announced that culling would be allowed in two pilot areas (West Gloucestershire and West Somerset), though it was subsequently postponed until 2013 to allow for better preparation. The culling - a combination of controlled shooting and cage trapping - started in July 2013 and was meant to last 6 weeks. The target was to cull $70 \%$ of badgers in the two pilot zones in the time allocated (6 weeks). However, it soon became clear that the target could not be reached. For example, according to the 2014 Report by IEP (the Independent Expert Panel) chaired by Prof Ranald Munro (from now on, Munro et al. 2014), in Gloucestershire only 708 badgers were killed (942 fewer than the target of 1650, less than $39.1 \%$ ). The reasons listed for the lack of effectiveness include the perturbation effect, the fact that the figures attached to the number of existing badgers in the area was miscalculated, and to some extent protesters' disruption. ${ }^{5}$ Besides, concern over the humaneness of killing was raised by the same report: it is extremely likely ( $95 \%$ in scale) that between 7.4 and $22.8 \%$, of shot badgers were reported to be still alive after $5 \mathrm{~min}$ of shooting and "therefore at risk of experiencing marked pain" (Munro et al. 2014, p. 51). Concern was also raised that contractors were not following Best Practice Guidelines in carrying out the shooting.

Government officials resorted to implementing an eight-week extension of the culling period (well into December 2013) in order to try to meet the target (Ares and Hawkins 2014; Ares and Pilbeam 2015). At the same time a lower target was suggested (53\%). However, the independent agency Natural England (the government's adviser for the natural environment in England) came to acknowledge that the target could never be met, even by granting an extension, and a lower cull target would force additional measures to be taken in the following year. At the same time, by implementing a 'diffused' type of culling further problems would come forward: if an insufficient number of badgers are killed over too long a period of time, badgers will end up roaming further afield in order to reconstitute their social networks, and they will end up spreading the infection further. ${ }^{6}$ Pilot culling in Gloucestershire and Somerset

\footnotetext{
${ }^{4}$ The results of the economic evaluation also speak against culling: the costs outweigh the benefits. And the benefits of culling in terms of disease control had already been declared poor by the results of the RBCT. So economic evaluation 'adds on' to scientific/experimental assessment.

${ }^{5}$ It was also suggested (not by IEP) that the reason of miscalculation was due to the fact that some illegal, unauthorised killing had been carried out in the meanwhile.

${ }^{6}$ Different additional culling methods have also been considered by the government: gassing badgers, or snaring them. In answering criticisms on the efficacy of the policy the Defra Minister O. Paterson told BBC Spotlight (9 October 2013) that dealing with wild animals is tricky, and in this particular instance badgers have moved 'the goalposts', undermining therefore the whole pilot cull. See http://www.bbc.co.uk/news/uk-england24462613
} 
resumed in September 2014, and as we write a new pilot scheme to test the efficacy, humaneness and safety of shooting badgers at night is due to start in autumn 2015 among yet to be resolved controversy.

But let us take a step back and ask why the government decided to disregard the recommendations in the Bourne et al. report and authorize the pilot culling.

\subsection{Using scientific advice and taking sides}

Right after the publication of Bourne et al. report Defra commissioned an assessment of the scientific evidence provided by that report to Sir David King, Chief Scientific Adviser to Government and Head of the Government Office for Science from 2000 to 2007. In his report (from now on, King et al. 2007) King reached a different conclusion from the team led by Bourne: culling badgers is the "best option available at the moment to reduce the reservoir of infection in wildlife." (King et al. 2007, p.4). Following the results of the RBCT, badgers are a clear source of infection for cattle, he claimed. They are responsible for $40 \%$ of infection in certain areas and the ISG 2007 Report clearly shows that where the trials were carried out, incidence of the disease significantly decreased. Cattle migrations and movements alone cannot explain the incidence and the increase of the disease. Of course culling should take place within strict parameters: it should occur where incidence of infection is high; it must be carried out alongside controls on cattle; it must cover an area of at least $100 \mathrm{~km}$ to take into account perturbation; and it should be conducted "humanely" by "competent operators" (King et al. 2007, p.5).

This conclusion, we read in King's report, is based on an evaluation focused on the "scientific basis" (King et al. 2007, p. 3), as government brief was to exclude "economic or other practical issues" (Environment, Food and Rural Affairs Committee, v.2, 2008, p. 101) - a specific and significant difference from how Bourne et al. reached their conclusions, as we will discuss further. King's conclusions were instrumental to support the implementation of the pilot badger culling that finally started in July 2013.

How was King's report received? Different sides reacted differently.

The scientific community was divided. ISG condemned King's conclusions, as these were a direct challenge to their views and recommendations on the matter (Bourne et al. 2007a). On one side, ISG criticized the narrow scope of King's brief in reaching his conclusions: he was asked to comment on scientific issues only, ignoring the wider context of issues and factors that crucially enter the problem of bovine TB. On the other side, ISG claimed that King made fundamental scientific errors in his use and interpretation of the scientific information and analyses in the ISG's final report. He was accused of incorrectly interpreting the significance of statistical confidence intervals, of excluding important data without justification, of failing to consider ecological data which supported the ISG's conclusions, of misunderstanding the mathematical modelling of TB and consequently under-estimating the benefits of cattle-based TB control measures. King was also accused of making a case for badger culling by relying on data from areas that were too small to be beneficial on the large scale, and without providing scientific evidence to support his advice.

Denis Mollison, an independent statistics expert auditor of the ISG's work, was among those who most vehemently condemned King. In a paper that takes issue against King's conclusions (Mollison 2007), Mollison says that Sir David King's report 
is "inexpert and unbalanced" because his group lacked the necessary expertise in "complex statistical modeling and data analysis". Mollison also claims that it takes only "a little bit of mathematics" to show that the Chief Scientist's conclusions are "one-sided", "muddled", "wrong", "untrue" and inadequate "as a basis for government action". If King had the courtesy to discuss his concerns about the ISG's work with the scientists themselves, he might have generated "more light and less heat."

Ian Boyd (Defra Chief Scientist advisor since 2012) was instead on King's side, though prudent in his conclusions. Embracing the view that badgers are part of the disease cycle in cattle (an evidence-based view) and their population density needs be reduced, more than King he emphasized that culling is not an end-in-itself policy option. However, Boyd argues, it is not up to the scientists to make government policy. Suggesting that it could be so would mean taking the place of politicians and immediately devalue scientific evidence.

"Strictly speaking, the role of science should be to provide information to those having to make decisions, including the public, and to ensure that the uncertainties around that information are made clear. When scientists start to stray into providing views about whether decisions based upon the evidence are right or wrong they risk being politicised. In general, it is important for scientists to stick to the evidence and its interpretation" (Boyd 2013). ${ }^{7}$

Outside science, King's views were welcomed by the farming industry. The deputy president of the National Farmers' Union, M. Raymond declared: "Now that we have scientific endorsement for the principle of badger culling there can be no further excuse for the government not to act." The farmers' support to King was seen by pro-badgers' quarters as confirmation that the government was one sided in matters of policy in this instance. For example, Trevor Lawson of the Badger Trust is reported as saying: "Professor King's list of recommendations repeat, virtually word for word, the opinions of farming unions and the cull-mad vets in Defra." ${ }^{8}$ The suggestion is that King's conclusions had been solicited by government officials who did not want to upset farmers by suggesting cattle culling as a better course of action or, more generally, alterations to their farming practices.

In the midst of all this, the public also started taking sides: campaigns were mounted to save badgers, pro-badger demonstrations were organized in different parts of the country, plans for disrupting the culling by animal rights groups went ahead in the pilot zones. Of the people who took part in an ITV Central's vote in the Midlands (27 September 2012) $92 \%$ proved to be against the badger cull. ${ }^{9}$ This confirmed a previous public consultation (2005), launched by the government on the principle of badger culling: of 47,472 responses $95.6 \%$ were opposed to a cull. The consultation also generated 13 petitions against culling, with a total of 12.100 signatures (Defra 2006, pp.4-5).

For the benefit of competent information, in 2006 Defra organised a series of 'citizen's panels', composed of members of the public, members of farming groups and campaign groups. The panels held one-day workshops where participants were

\footnotetext{
${ }^{7} \mathrm{http} / / /$ elifesciences.org/content/2/e01061. This is an interesting viewpoint, to which I shall return later.

${ }^{8}$ Both reported on The Guardian, Tuesday 23 October 2007 by J. Randerson, science correspondent, ('Science adviser backs selective badger culls').

${ }^{9} \mathrm{http}: / / w w w . i t v . c o m / n e w s / c e n t r a l /$ story/2012-09-26/badger-cull-protest/
} 
introduced to the relevant issues and discussed them with experts. The outcome of these workshops was a fifty-fifty split on the principle of badger culling, and those who were in favour of culling shared the view that culling had to be only one in a range of measures dealing with the disease (Defra 2006, p.10). The Badger Trust and RSCPA felt therefore encouraged to campaign even harder against culling in the press.

Badger culling policy fast became, and continues to be, one of the most heated and hated policies in the UK.

\section{Being objective, among other things}

What can we learn about the use of science in policy making from the case study just illustrated?

First of all, scientists were brought into the bovine TB debate to investigate the most significant causes of the spread of the disease and to make predictions as to whether certain measures to contain the disease would be effective. In particular they were asked whether badgers are such causes, and whether culling badgers would in time effectively control the disease in cattle.

Establishing scientific causes and making fact-informed predictions about effectiveness, both achieved by means of valid, precise, rigorous methods of inquiry, are intended to provide a policy process with 'objective grounds' for deliberating about what to do (or about whether doing a particular thing is worthwhile).

Objective in what sense? The apparatus of science (the use of experiment, measurement, causal analysis) is apt to secure results concerning matters of fact in a way that is the opposite of being speculative (unfalsifiable), unwarranted, imprecise. Scientific facts (i.e. the facts acquired by science) are in this sense objectively established (or have the potential to be so established) by the apparatus of science. So when we hear that badgers contribute by $40 \%$ to the spread of bovine TB, or that the phenomenon of perturbation reduces the chances of success of a badger cull by xyz $\%$, we are willing to rely on these claims (or are prepared to grant credence to them) as they are based on facts that are the result of objective scientific investigation.

However, there are at least two aspects to consider. First, using the same methodological tools and apparata does not guarantee uncontroversial results. If scientific facts are contested, we fear for the objectivity of any given scientific result. Among the scientists consulted in the bovine TB debate there is relative consensus on the fact that badgers are a cause of infection, but major disagreement creeps in when the scientists predict whether, were badgers to be culled, the disease would recede. For the ISG scientists of the 2007 Report the fact of perturbation, along with some crucial economic and practical constraints on implementing a cull, work against the effectiveness of culling in the given circumstances. In King's report we are told instead that were perturbation be taken care of (eg., the area of culling should extend as far as 100 square $\mathrm{km}$ from the epicenter of a disease outburst, to anticipate and control badger behaviour consequent to culling), and even without resorting to the "practicalities" of cull implementation, predictions on cull effectiveness can be made.

Second, and somehow in parallel, scientists might differ in their use of scientific methods and tools: disagreement here includes (more or less robustly justified) 
differences on how to interpret or construct the evidence. 'Differences' sometimes are labeled more critically, as when for example a scientist is accused by fellow scientists of making 'fundamental scientific errors' in assessing the facts. This happened in the bovine TB case: King, as we saw earlier, was accused of providing mistaken conclusions ("one-sided", "muddled", "wrong", "untrue"), due to lack of either competence or understanding of methods and scientific tools. Here we are even farther away from the objectivity science (and scientists) should secure to its (their) results.

The expectation that science provides a policy process with objective grounds does not immediately match with an outcome of widespread consensus among the scientists. Disagreement within science is part and parcel of how scientific inquiry proceeds. Still, any disagreement among scientific claims might drive us towards fearing a lack of certainty or robustness regarding the very facts those claims are about, and objectivity would immediately suffer as a result.

There is a third thought that complicates things further. Disagreement among scientists does not emerge only from a different interpretation of facts, or a different use of methods and scientific tools of inquiry. When science enters policy making, it might also express differences in the policy agenda the scientists (more or less tacitly) subscribe to. I do not mean this in the sense that disagreement reflects the political inclinations of the scientists involved in a specific policy dispute. More specifically I point at the different views they might hold of how scientific inquiry can contribute to policy. The scientists find themselves facing a dilemma: should they just inform, or should they also advise on what to do in policy terms?

The ISG 2007 Report on one side, brings forward the view that science can provide "clarity, precision and rigour" on a range of crucial issues of evidence. On the other side, it also supports the view that, by being able to engage with a wideranging scope of aspects related to bovine TB (economic, social, environmental, legal, technological), science should inform as well as advise. As we read in the Report:

'(...) while confirming its commitment to the scientific approach, the ISG identified its core aim as being "to present Ministers with a range of scientifically based policy options which will be technically, environmentally, socially and economically acceptable" (quote from Bourne et al. 1998, p. 4)' (Bourne et al. 2007b, p.33).

A rather different position emerges from scientists such as Boyd, who - as we saw above - claims that in evidence-based policy science should inform on matters of fact that pertain to science and restrain from advising on what policies are right or wrong (or what policies are right or wrong to pursue). This position is echoed from the policy/politics' side when we read for example in the 2011 government policy document that a prediction on the effectiveness and sustainability of culling badgers by the farming industry is 'a matter of judgement, not of science'. ${ }^{10}$ What we evince from this claim is a combined view that 1) scientists have not the right type of knowledge and expertise to make such types of predictions and 2) by mixing

\footnotetext{
10 "It is a matter of judgment, not of science, whether the farming industry can deliver an effective, coordinated and sustained cull." (Defra 2011, p.11).
} 
science and judgement (in particular, judgment that it is not for them to produce) scientists would be less reliable, less credible.

It is presumably in this spirit that the Government directed King to consider 'exclusively scientific' evidence, and it is on the basis of this evidence alone that King claims that culling badgers can be an effective measure of containment.

If we compare ISG's and King's underlying reasoning, in both cases it appears of the following sort:

Given that badgers are a significant cause of infection (agreed), culling badgers might help contain the spread of the disease (partially agreed) - provided that effective culling can be implemented.

A major part of disagreement arises with the proviso. The ISG scientists believe, on the basis of their assessment, that effectiveness cannot be achieved (for reasons partly scientific, partly economic, partly practical). King does not directly engage with the proviso: scientific evidence can only establish that, if badgers were effectively culled, then the disease would recede, and that a cull, to be effective, should entail a series of features. The feasibility of implementation is a problem for the government, not for the scientists.

The worry we face here can be captured by the following question: to what extent can science engage with policy decision making without compromising the rigour and impartiality of its contribution?

The disagreement about how to pitch the role of scientific inquiry in policy making ought to be handled with care. First of all, separating drastically science from judgement seems to deny one of the reasons why science is indeed used in this dispute (and in so many others): to help decide what to do. This does not mean that the scientists should take the place of the policy makers or of the politicians, but that their judgement matters as much as their science, or better it matters as it is a judgement that does not come out of sheer, unwarranted speculation. The ISG scientists' answer to whether the farming industry could deliver an effective, coordinated and sustained badger cull was formulated in terms of a prediction based partly on 'scientific' facts concerning culling strategies (eg. perturbation, etc.), and partly on other considerations such as economic factors (costs of culling programmes vs. available resources vs. a wide range of unequally distributed benefits etc.). The scientists' prediction in this case is their judgement.

Secondly, and more generally, in producing good, solid scientific evidence with a view to using it in areas of practical/social concern scientists cannot keep the realm of judgement at bay. The facts provided by ISG scientists in the bovine TB dispute were researched and discovered with a view to answering specific policy questions and making specific predictions. This process is inevitably paved with choices and judgments, as for example when scientists assess the relevance and comparative weight of the facts (more or less known or certain) to be included or excluded from a prediction - with a great degree of variation among scientists as to what facts to emphasize, what methods to use to compare them, etc. Policy makers make their own judgments - in assessing scientists' assessments, and in assessing how other factors (other than scientific facts, eg. economic, political, legal, social, ideological) might affect options in practice. The scientists themselves - as for example the members 
of ISG - are not unaware that 'other factors' also enter the way they assess and judge the evidence they provide. ${ }^{11}$

However, a sense of uneasiness creeps in, especially in the case of scientists: it seems that once scientists let judgement in (or too much of it) they trespass the boundaries of their profession, and by so doing they betray their mandate (i.e., bringing objectivity to the process).

The worries brought out by analyzing the different sources and consequences of disagreement among scientists, and between science and policy, should not be left unaddressed. It is not part of this paper to decide whether and how we are dealing with competent, reliable scientists, or what is a better or worse method or technique to produce the data we are after. It is instead an essential part of the argument we are articulating to figure out the contribution of purportedly adequate scientists to the effectiveness of policy decisions, given that these are taken in a context that by necessity includes features and considerations that go well beyond scientific evidence.

A first step towards dealing with our worries (and possibly resolving them) is then to consider the range of practical matters that seem to fall outside the remit of scientific advice and yet inescapably belong to any framework of policy decision-making. What we find in this range are economic considerations, the feasibility of certain technologies of management, the practical implementation of certain courses of action; but also values, ideologies, and common sense views. In the next section I will analyse some of the challenges coming from paying attention to these matters, and how they can be handled by building an inclusive context of action. This will allow me to bring my argument to a conclusion in favour of retaining a version of objectivity that can still be of some use in the realm of social and political practice.

\section{Objectivity 'on balance'}

Are our worries concerning the relation between scientific evidence and policy context justified? Does the practical context in which policy making takes place act as a limit to science's contribution to policy, and in what sense?

We have seen that one of the questions the scientists addressed in the 2007 Report was whether the farming industry could deliver an effective, coordinated and sustained badger cull. The answer was formulated in terms of a prediction based partly on 'scientific' facts (eg. data concerning badgers' behavior consequent to culling strategies), and partly on economic considerations (costs of eradication programmes vs. available resources vs. benefits in terms of some public interest), ethical concerns (cattle's welfare against badgers' protection), and social effects (impact on the farming community and their rights vs. animal rights groups fighting for animals' interests). The underlying idea is that all these different facts, factors and considerations should be taken into account,

\footnotetext{
${ }^{11}$ Policy makers as well as scientists make practical judgements, in the Aristotelian sense (Nicomachean Ethics, Bk VI) of pointing in the direction of "knowing the right thing to do, at the right time, in the right way, and for the right reason." Knowing what is right (in the circumstances) is different from, simply, knowing (eg, in the case of scientists, being knowledgeable in some disciplinary field/s). It entails being able to put knowledge to the right use (in the circumstances). Aristotle famously treated this skill as a form of wisdom (phronesis).
} 
weighted against each other and entered in a framework of judgment that appears not only well informed, but also well 'balanced'.

An idea, or ideal, of balance was explicitly pursued, for example, by Defra in establishing the 'Bovine TB Advisory Group to Ministers' (2006). Membership of the group was intended to reflect different backgrounds and interests, in view of ensuring "a balance of experience across farming, veterinary, conservation and welfare issues". ${ }^{12}$ Its aim was to listen to the contrasting views and concerns of all interested organisations and advise the Government to reach a well-informed, objective picture of the issues to consider, giving each of them equal attention. Of course, creating a working group with these characteristics and intents cannot guarantee that any balance will be reached in practice, or that it will prove effective in achieving the appropriate decisions. Nonetheless, the idea of a 'balance' deserves our attention because - if appropriately spelled out - I believe it might help to put some of our worries concerning objectivity in the right perspective. In what follows I will try first to confront some of these worries in detail, and in the process rectify - as far as possible - the extent to which they impede our capacity to plead for objectivity.

Let us first remind ourselves that in the realm of practice scientific evidence (more or less certain, contested, controversial, value-laden) is to be taken into account in a context where other relevant factors intervene (political, social, economic, ethical, etc.). ${ }^{13}$ As a consequence, two aspects emerge concomitantly, though potentially as a mutual source of tension.

On one side, if a policy decision does not properly evaluate the context where the decision is taken - that includes a series of questions that transcend the objectivity of the facts put forward by science - the worry is that the decision is not inclusive, and just. Fairness is an aspect that sits well in a definition of practical objectivity, but is irrelevant in a definition of scientific objectivity.

On the other side, if we expose the facts of science to a consideration of fairness (and by so doing, open the door to a whole series of factors that transcend the establishment of scientific facts) the worry is that science loses the objectivity of its assessment of facts. ${ }^{14}$ Reliability of facts sits well in a definition of scientific objectivity, but confronts practical objectivity only after a question of relevance, use and goal of facts has been settled.

\footnotetext{
$\overline{12}$ See http://archive.defra.gov.uk/foodfarm/farmanimal/diseases/atoz/tb/partnership/advisorygroup.htm

After nearly three years of work the group wrote a final report, 'Bovine Tuberculosis in England: Towards Eradication - April 2009'. The group is no longer active. Other working groups took its place.

${ }^{13}$ This is why, for example, there is room for criticism of some formulations of evidence-based policy: too much emphasis on 'evidence' (as in scientific evidence), as if it were the only/best adjudicating factor in a policy, can be misleading. This is at least for two reasons. Firstly, as we have just mentioned, there is not only scientific evidence to consider in matters of policy. Secondly, even when we focus on scientific evidence alone, there is more than science in so-called 'scientific evidence'. Scientific facts do not come with a label that marks them as 'evidence'. To count as evidence they need to be made relevant to the particular situation they are meant to provide evidence for, and - as we learn from the bovine TB case - this requires a wider apparatus of hypotheses, judgements, decisions, and evaluations. These issues are widely discussed in Cartwright and Hardie 2012; and Montuschi 2009.

14 This is indeed part of King's criticism of Bourne and Co.: they included aspects in their predictions that do not pertain to scientific evidence. This is also part of the government's criticism to Bourne: science must not drive policy, it must only inform it by sticking to facts that fall within its own domain of competence.
} 
The tension between these two aspects is one type of difficulty that a good analysis of a concept of 'balance' can help us overcome, allowing us to envisage what a view of objectivity that is both practical and practicable might look like.

How can balance be achieved? A useful starting point is to see what cannot be of use in achieving it, because at the same time it makes us grasp why an idea of objectivity 'on balance' might create some worrying feelings.

First, balance cannot be achieved by following rules. If we try to fix a food processor then the rule 'insert a particular spring in a particular part of its engine, then the problem will be fixed' will be effective. This of course does not apply in, say, the bovine TB dispute. Here we deal with a complex context or frame of interaction for badgers, cattle and humans - a 'wicked environment' - or better, a series of environments - that makes it difficult to predict what is really needed to 'fix' the problem (Hogarth 2004; Kahneman 2011, p.241). We do not know, for example, how many factors - from badger population closure to effectiveness of controlled shooting to protestor activity, etc. - can intervene in biasing any one estimate of methods of culling, and how each of these factors affects the degree of certainty or robustness of those estimates (Munro et al. 2014, p.39).

Besides, the different facts and factors, coming from different sources and different contexts, do not operate in isolation. Yet, it is not simply a matter of 'adding them up'. They need to be made mutually relevant in a coherent way, if we want them to tell a convincing story about whether, say, cage trapping is effective, or how safe, or else 'humane', controlled shooting is.

Coherence is not just a matter of logic: it is a matter of context and judgement. There is no manual that teaches us how to combine different facts and factors in all and any circumstances - even when we evaluate and compare situations we deem similar or recurrent for certain aspects (eg. behavioral traits of badgers). In other words, we do not have a safe standard of measurement, when it comes to weighing evidence and all the factors in the frame of which evidence is to be evaluated.

Achieving a balance of all the evidence available (more or less established, more or less comparable by similar means) is a complicated process that relies on what for example N. Cartwright calls 'supportive factors' - a whole team of local conditions that in specific circumstances help us achieve a balance (Cartwright and Hardie 2012, p.25). A supportive factor is a sort of INUS condition ${ }^{15}$ (Mackie 1965): it is an indispensable (i.e. necessary) member of a set of conditions that are jointly sufficient for achieving a result, although these conditions are not themselves necessary for achieving that very result.

The role of supportive factors brings attention to the fact that each balancing act is an act of its own, that requires specific and local conditions induced by the circumstances where the act takes place. For example, to ensure effectiveness of shooting a minimum distance from badger setts should be respected, but how minimum depends on individual setts, and on badger activity within different setts, etc. Nonetheless, even measurable effective shooting in one or more setts does not secure an overall result in terms of effective containment of the disease, since yet other factors might (and do) enter the picture and 'perturb' the expected general outcome.

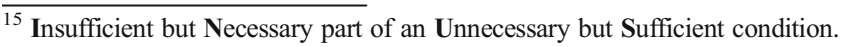


Second, balance is not equivalent to certainty (on the positive expectation that the more certain an outcome the more objective, or that certainty is the exclusive mark of objectivity). If it were to be the case, we would be inclined to select and rely only on those facts or factors that can be treated by methods designed to deliver certain results (according to a particular view of rigour, eg. mathematical or statistical). At the same time we would underestimate everything that cannot be treated by the same means. For example, since there are no algorithms to include values, values would automatically be left out of the balancing process. In the bovine TB case, how can we include the 'myth of the old rogue badger' that purportedly had an effect on public policy?

'The concept of the 'rogue badger' permitted the construction of an image of a bad, deviant and antisocial badger, a 'senile and virtually toothless creature' whose actions could be presented as a basis for intervention against a cherished animal' (Grant 2009, p.563).

This image of the badger is in striking contrast to the more sympathetic one adopted by animal protection groups, or by a large part of public opinion. However, given that the values and ideologies that drive these images cannot be 'measured' in the way, say, genetic profiling or likelihood of outcomes of badger trapping can be, the discussion on intervention and remedies is constrained to grounds that appear amenable to more robust analysis. Whatever is taken to be non analyzable by the same means is sidetracked.

Alternatively, even when we try to analyze the role of values in a rigorous way we might be tempted to force them into well established methods that only draw our attention to what these very methods can deliver (which might not be what is really relevant or interesting about the values we want to include). For example, testing whether the presence or absence of a certain image of badgers affects the type of policy pursued on bovine TB might neglect to address whether this image is real, whether it has any reason (and of what sort) to be accepted in the first place, in what contexts - social, political, ethical - it took shape, etc.

Third, balance is not a methodological standard or a protocol. It is rather an act, driven by a particular type of reasoning that we could call 'deliberation'. ${ }^{16}$ Deliberation concerning public affairs is not a deductive, certain, strictly inferential type of reasoning, or to a large extent independent of who the reasoner is. It comes about while considering and pondering over all sorts of things (facts and opinions and values etc.) and it is led by individuals, different types of individuals (scientists, policy makers, experts, citizens) who possess a number of intellectual and practical virtues put to the service of reaching a particular view or decision (Cartwright and Hardie 2012, p.159).

We here rejoin the importance of judgement. Deliberation requires judgement, not rules (or not simply rules). In what sense? Think for example of those decision-making tools that help us in setting out systematically what our options are, such as decision trees. A decision tree is a tree-like graph conceived in view of mapping out possible plans of actions and in the light of the possible outcomes and consequences associated with each plan. Probabilities are assigned to each possible outcome, and values are attributed to each outcome. The aim of the graph is to identify our best options, our best decisions (Fig. 1).

However, no matter how reassuring these tools might be (they look impersonal, and therefore objective), they come to the rescue after most of the hard work has been completed - that is, choosing the alternatives, guessing the probabilities, attaching utilities to outcomes, etc.

\footnotetext{
${ }^{16}$ Not as used in deliberative democracy. See below.
} 


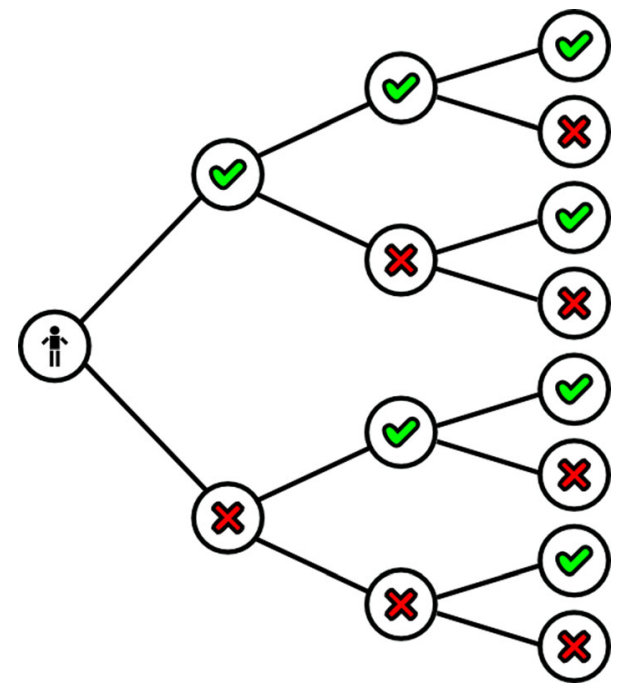

Fig. 1 Graph sample of decision tree

In the bovine TB case, deciding on what courses of action might enter a virtual tree (culling or not culling; or partially culling combined with vaccination of either cattle or badgers; culling by what method - cage trapping vs. shooting vs. gassing vs. snaring; etc.) is not uncontroversial, and neither is attaching probabilities of success or failure to each alternative. These choices are made on the basis of judgement, experience, perception or expertise - none of which is guaranteed by objective rules of method, or by diagrams. If a path in the tree might suitably assist us in calculating the desirability of a choice once this is identified, it cannot equally assist us in 'choosing our choice' in the first place (culling badgers is not an option for everybody, no matter how successful in percentage its outcomes might prove to be), nor the desirability of all those factors that make the outcome desirable.

At this point we start seeing our worries more clearly: if so many extra local conditions and so many amendments are needed, if so much room for discretion and judgement is required by the practical contexts of policy deliberation, can we still retain transparency of conduct (in the absence of rules, for example), accountability and impartiality of results (when methodological standards cannot guarantee and secure the fairness of decisions), restraint from prejudice (when judgement rather than method plays a large part in reaching a result), etc.? Does it still make sense to retain the whole idea of 'being objective' in the messy world of decisions and choices? Would anybody notice, or even care, if the very idea were scraped away from the goals of policy making? What would we be left with to reassure us that we are doing 'the right thing'?

\section{Why It Matters: A plea for a practical theory of objectivity}

In this paper I analysed the way/s by which science contributes to achieving objectivity in policy making and social debate, with the understanding that objectivity is not exhausted by what science has to contribute to either. 
Policy making is a complex activity. Scientific evidence is only one of its building blocks, along with attention paid to social, ethical, cultural, legal, economic, and not least ideological or even electoral considerations.

The objectivity pursued in a practical context of decision-making (practical objectivity, from now on PO) differs from scientific objectivity (SO) in at least the three following aspects:

- $\quad$ PO is an inclusive rather than exclusive concept (the special sense of SO tends to exclude any factor that is not established by the best tools of inquiry in science, eg. measurement and experiment).

- PO is aim-sensitive rather than aim-neutral (in science 'what is true is true', independently of what it is 'true for').

- PO is an achievement rather than a protocol of research (in science the meaning of objectivity is normatively established in advance of the process that shows what it takes to pursue a given aim).

The difference between the two types of objectivity does not entail that they are in conflict and/or that they should be kept apart. Practical objectivity has itself a role to play in science - as we have seen, scientists not only measure and experiment but judge and deliberate - and scientific objectivity is, and indeed ought to be, called upon to inform practical decisions. What it means, though, is that we should not expect that reliable decisions can simply be 'read out' of scientific facts, and that we should instead be prepared to consider and evaluate how reliable decisions turn out to be (and what 'reliable' means), in the light of a range of factors intervening from outside the domain of science. Blurring these two roles plays a disservice both to science and to policy.

In the realm of practice, to be objective is an act of balancing judgements and containing worries. It pays attention to different sources of information and tries to combine them, even when they potentially feed on disagreement. Combinations can make use of formal tools but their outcomes cannot rely entirely on them. Contextual and local considerations will always fill the gap left by protocols and general rules.

However, it might be objected that insisting too much on the role of disagreement and of practical and local considerations ends up weakening the constraints on what can legitimately enter the decision-making process (anything goes?). So, does PO conceived along the parameters suggested in this article have any prospect, or any real function in social debates? Is it too broad, and yet satisfactory an answer to the sceptic and the disillusioned? A few concluding remarks will help to put the argument developed so far in perspective, and suggest a possible direction to take in future research in studies on 'practical objectivity'.

An important and well-acknowledged strategy of discussion in modern liberal democratic societies is the appeal to facts. Facts, by definition, transcend individual idiosyncrasies. Facts are for all and speak for all. Facts - even when there is disagreement among them - ensure a civil confrontation of opinions, and a discussion led on shared and accountable ground rules. Different contexts may require different, non generalizable conditions and local factors to achieve a shared framework of factual appeal in each and every specific context, but this is as far as we can go in imagining how debates informed and driven by objective discussion might look like. 
In Political Liberalism John Rawls suggests five essential requirements (which he believes are widely recognized) for what he calls a "public conception of objectivity" (Rawls 1993, pp.110-112). First, it must establish a "public framework of thought" that makes it possible to form judgements and reach conclusions "on the basis of mutually recognized criteria and evidence". So, objectivity is not a matter of rhetoric, opinion, or power, but the outcome of a genuine and shared methodologically driven debate. Second, and as a corollary of the first requirement, the judgements and their conclusions must aim at being correct. Correct means in Rawls's terms reasonable, that is "supported by the preponderance of reasons specified by the principles of right and justice issuing from a procedure that correctly formulates the principles of practical reason in union with appropriate conceptions of society and person". In other words, a reasonable judgment is ultimately a just one - just in relation to commonly held principles, and just vis a vis commonly recognised procedures for acquiring those principles. Third, a conception of objectivity should entail an idea of "an order of reasons", weighed and ranked by agents who are expected to act in accordance with them (whether they individually like them or not). Fourth, and again as a corollary of the previous requirement, a conception of objectivity should allow us to distinguish between an objective point of view (as so defined by "reasonable and rational agents") and the point of view of a particular agent. "It is part of understanding the concept of objectivity that we never suppose that our thinking something is just or reasonable, or a group's thinking so, makes it so". Fifth, a conception of objectivity must rest on "an account of agreement in judgment among reasonable agents", which means that if reasonable agents possess the same information and share the same criteria of judgement then "they will reach the same (or a similar) conclusion".

By recalling Rawls' five requirements I do not intend to open a discussion on the validity or political insight of each and all of them - a task far beyond the scope of the present paper. It just suits the more limited purpose of providing a suggestion on how to position SO vis a vis PO in the argument of this paper. Of the five requirements - public framework of thought, correctness of judgement, ranking of reasons, distinction between the politically subjective and objective viewpoint and reasonable agreement - only the first, by Rawls's own admission, is generalizable to all types of inquiries, there included scientific inquiries. As mentioned above in this section, an appeal to facts and shared access to method(s) to deal with them is a pre-requisite for making objective judgements of all sorts. This however does not preclude that, if science is thought of as being useful in public debate, the remaining four requirements are also relevant to the way science takes part in that debate. At the very least, the four remaining requirements specify the features of the framework for the public discussions science is asked to contribute to. SO should demonstrate that it is able to enter a fruitful dialogue with PO - by weighing correctness and fairness, by negotiating the criteria that allow for a reasonable resolution of disagreement, and by assessing the practical reasons for accepting a publicly acknowledged conception of objective judgement.

\subsection{Brief epilogue}

When the Secretary of State for Environment, Food and Rural Affairs Owen Paterson was questioned over the purported failure of the 2013 pilot culling policy, and accused 
of constantly moving the goalposts of his policy, he claimed that it was badgers that "have indeed moved the goalposts". Objectivity in public affairs is a little like Paterson's badgers. It spoils the party. It looks good on paper, but it does not work quite as expected when confronted by the vagaries and challenges of the real world. Like the badger, it is a wild card. One of those cards though that - if we learn how to treat and respect it - can indeed make a difference to whether our policies work effectively and safely.

Open Access This article is distributed under the terms of the Creative Commons Attribution 4.0 International License (http://creativecommons.org/licenses/by/4.0/), which permits unrestricted use, distribution, and reproduction in any medium, provided you give appropriate credit to the original author(s) and the source, provide a link to the Creative Commons license, and indicate if changes were made.

\section{References}

Ares, E., and Hawkins, O. (2014). Badger culling: TB control policy. London: Library of The House of Commons, SNSC-5873.

Ares, E., and Pilbeam, C. (2015). Badger culling: controlled shooting pilots. London: Library of The House of Commons, SNSC-6387.

Bourne, J., Donnelly, C. A., Cox, D. R., Gettinby, G., McInerney, J. P., Morrison, W. I., et al. (1998). Towards a sustainable policy to control TB in cattle: A scientific initiative. MAFF London: First Report of the Independent scientific Group on Cattle TB. PB3881.

Bourne, F. J., Donnelly, C. A., et al. (2007a). Response to "tuberculosis in cattle and badgers: A report by the chief scientific adviser. Memoranda to the Enviornment Food and Rural Affairs Committee House of Commons.

Bourne, J., et al. (2007b). Bovine TB: The scientific evidence', Final Report of the Independent Scientific Group. London: Defra.

Boyd, I. (2013). Point of view: Making science count in government, eLife 2013; 2:e1061; http://elifesciences. org/content/2/e01061.

Cartwright, N., \& Hardie, J. (2012). Evidence-based policy. A practical guide to doing it better. Oxford/New York: Oxford University Press.

Daston, L., and Galison, P. (2007). Objectivity. New York: Zone Books.

Defra (2006). Public Consultation on Controlling the Spread of Bovine Tubercolosis in Cattle in High Incidence Areas in England: A report on Citizens' Panels.

Defra (2011). The Governemnt's Policy on bovine TB and badger control in England.

Environment, Food and Rural Affairs Committee. (2008). Badgers and cattle TB: The final report of the independent scientific group on cattle TB. Fourth Report of Session 2007-2008, v.2. House of Common London: The Stationary Office Ltd.

Gilbert, M., et al. (2005). Cattle movements and bovine tuberculosis in Great Britain. Nature, 435, 491-496.

Gopal, R., et al. (2006). Introduction of bovine tuberculosis to north-east England by bought-in cattle. Veterinary Record, 159(9), 265-271.

Grant, W. (2009). Intractable policy failure: the case of bovine TB and badgers. The British Journal of Politics and International Relations, 11(4), 557-573.

Hogarth, R. (2004). Deciding analytically or trusting your intuition? The advantages and disadvantages of analytic and intuitive thought. In T. Betsch \& S. Haberstroh (Eds.), The routines of decision making. New York/Hove: Psychology Press.

Kahneman, D. (2011). Thinking, Fast and Slow (p. 241). New York: Farrar, Straus and Giroux.

King, D. et al. (2007). Bovine tuberculosis in cattle and badgers

Krebs, J., et al. (1998). Bovine tuberculosis in cattle and badgers. In Report by The Independent Scientific Group. London: Defra.

Mackie, J. L. (1965). Causes and conditions. American Philosophical Quarterly, 2(4), 245-264.

Mollison, D. (2007). TB in cattle and badgers: comments on the chief scientific Adviser's report and on the ISG's response.

Montuschi, E. (2003). The objects of social science. London/New York: Continuum Press.

Montuschi, E. (2009). Questions of evidence in evidence-based policy. Axiomathes, 19(4), 425-439. 
Montuschi, E. (2014). Scientific Objectivity. In N. Cartwright \& E. Montuschi (Eds.), Philosophy of Social Science. Oxford: Oxford University Press.

Munro, R. et al. (2014). Pilot Badger culls in Somerset and Gloucestershire report, The Independent Expert Panel, www.gov.uk/governement/publications

Randerson, J. (2007). Science adviser backs selective badger culls, The Guardian, Tuesday 23 October 2007. Rawls, J. (1993). Political liberalism. New York: Columbia University Press. 